\title{
Dynamic heating and ventilation of transformer substation buildings with adjustable resistance to heat transfer in windows
}

\author{
Andrey A. Yablokov ${ }^{1}$, Nikolay N. Smirnov ${ }^{1, *}$, Vladimir V. Tyutikov ${ }^{1}$, and \\ Vladimir A. Gorbunov ${ }^{1}$ \\ ${ }^{1}$ Ivanovo State Power Engineering University, 153003 Ivanovo, Russia
}

\begin{abstract}
The article considers issues related to providing dynamic heating and ventilation of transformer substation buildings featuring designed digital voltage transformers demanding particular ambient temperatures. We have shown the efficiency of using heat reflecting screens in windows with lower transmission heat losses from the transformer substation buildings concerned.
\end{abstract}

\section{Introduction}

As we know, the reserves of fossil fuels such as natural gas, coal and oil are limited and, according to different forecasts, will be exhausted within a few centuries $[1,2]$.

At electric power substations, it is essential to maintain such indoor environment parameters as will ensure comfortable working conditions for equipment and personnel. Special requirements regarding indoor thermal balance apply in the case of equipment related to relay protection systems, power and measuring transformers. Proper air renewal inside buildings must be provided during the warm season to ensure normal operation of digital transformers featuring a resistive voltage divider [3] and prevent overheating of resistive elements [4].

With regard to substation personnel, we have to note that in buildings where people are con-stantly present it is essential not only to maintain indoor environment parameters, but to reduce fatigue among personnel. In industries characterised by monotonous and stressful work, stable indoor environment conditions lead to increased fatigue among personnel and lower labour efficiency. A dynamic indoor environment system (DIE) [5], which increases capacity for work by stimulating the central nervous system, supplies air with parameters that constantly change with time. A dynamic indoor heating system $(\mathrm{DH})$ also promotes lower levels of fatigue among personnel and better attention to and concentration on their tasks.

Reduction of electric heating costs in electric substation buildings demands reduced transmission heat losses via windows by using heat reflecting screens installed in the windows [6]. It is essential to examine the impact of the techniques related to using

\footnotetext{
${ }^{*}$ Corresponding author: nsmirnov@bk.ru
} 
windows with screens as developed by the authors on the indoor environment in transformer substation buildings.

\section{Ventilation and heating systems in various types of substation buildings}

Heating is not envisaged during the cold season in buildings housing power and measuring transformers (see Fig. 1) and in reactor chambers, due to large heat release.

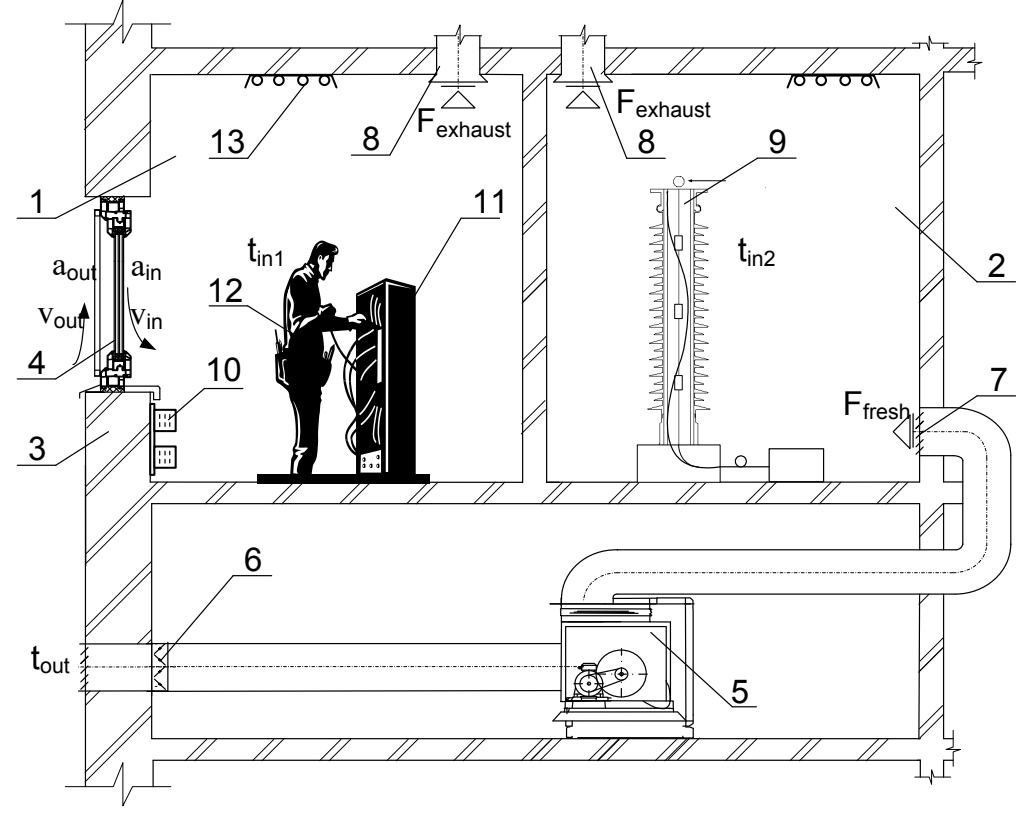

Fig. 1. System for maintaining a technologically appropriate and comfortable indoor environment in substation buildings with adjustable resistance to heat transfer in windows: 1 - heated building; 2 - transformer chamber; 3 - wall; 4 - window with externally mounted panel type heat reflecting screen; 5 - ventilation unit; 6 - adjustable shutters with electric drive; 7 - air inlet screen; 8 - extract duct; 9 - digital transformer; 10 - heating devices (electric heaters); 11 - relay panels; 12 maintenance personnel; 13 - lighting.

During the warm season, to remove excess heat from working transformers (including those based on resistive voltage dividers), combined extract and input ventilation units are provided, usually with mechanical air input and natural extract air. Our simulation of transformer thermal condition and numerical solution methods [4] enable us to formulate and solve tasks related to choosing optimal transformer design (Fig. 2) and operation modes to ensure the most accurate measurements in the course of limiting the thermal condition of resistive elements, and also to calculate the required air renewal in the building. This approach enables us to develop technological measures aimed at increasing the reliability and prolonging the service life of transformers featuring resistive voltage dividers.

A verified mathematical digital transformer simulation with COMSOL Multiphysics software was used to study the thermal field of a digital transformer featuring a resistive voltage divider to determine the location of resistive elements that results in their minimal self heating.

Our studies showed that moving the resistive divider to the inner insulator wall permits reduction of resistive element temperature from $81{ }^{\circ} \mathrm{C}$ to $54{ }^{\circ} \mathrm{C}$, with a further reduction by $3.4{ }^{\circ} \mathrm{C}$ if resistive elements are positioned in a spiral. 


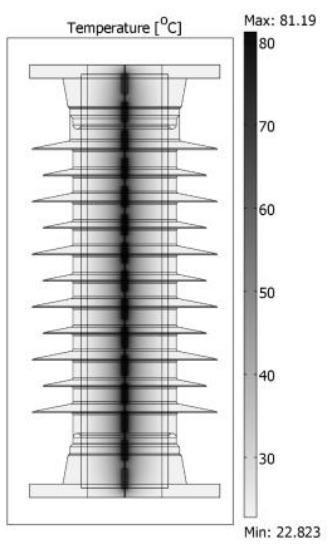

a)

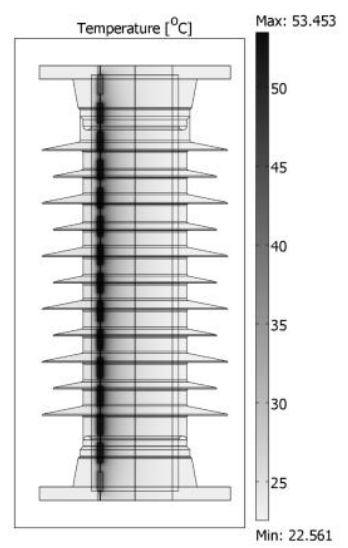

b)

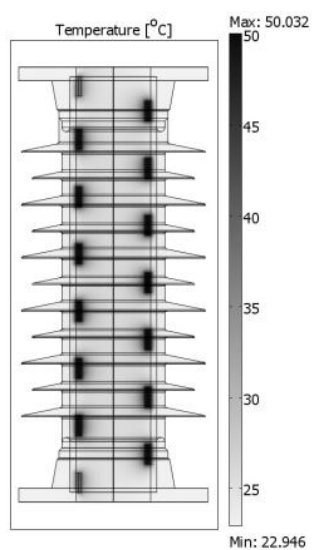

c)

Fig. 2. Comparing thermal fields in a transformer featuring a resistive divider with axial (a), edge (b) and spiral (c)positioning of resistive elements.

Physical diagnostics of the thermal condition of digital voltage and current transformers (Fig. 1, item 9), involved in laboratory and commercial recording of electric power consumption also create a better understanding of the role of such measuring equipment in the thermal balance of electric substation buildings.

Heated premises (for example, relay panel facilities, workshops etc.) are provided with heating devices such as electric heaters, with automatic control from temperature sensors installed on the premises, and by means of an algorithm maintaining dynamic heating mode. Dynamic heating improves work capacity and attention among personnel engaged in intense and monotonous work during a work shift. Both normal (constant) and emergency ventilation of the heated premises are envisaged.

\section{Developing techniques of using heat reflecting screens in windows. Results of testing these screens in windows}

Staff from ISPEU and the National Applied Sciences Institute in Strasbourg (INSA de Strasbourg) have developed and patented windows designed with roll, jalousie and panel type heat reflecting screens made of metal $[6,7]$. These significantly reduce transmission heat losses. The use of such screens is convenient at night, or in the absence of people. Fig. 1 shows an example of a panel type heat reflecting screen mounted on the outer surface of a window (item 4) in a heated building where required air parameters are maintained with the help of a heating and ventilating system. The use of such screens not only reduces transmission heat losses, but also permits lower ambient during setback heating mode [6].

In the course of mathematical simulation and physical experiments, it was proved [7] that in windows with heat reflecting screens not only is two-position control of resistance to heat transfer $R_{0}$ provided by moving the screens, but, as is evident from simulation data (Fig. 3, a), the given (and thermal) resistance to heat transfer depends to an even greater degree on the difference between indoor and outdoor air temperature, $\Delta t$. Moreover, this difference becomes more pronounced as the number of screens is increased. The value of transmission heat losses through windows is also a non-linear value (see Fig. 3, item 6). 


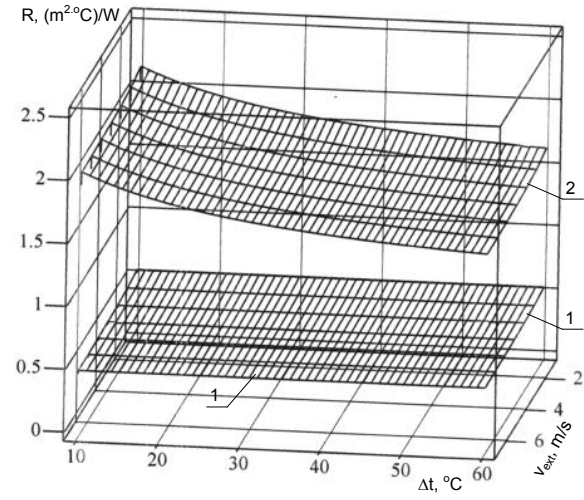

a)

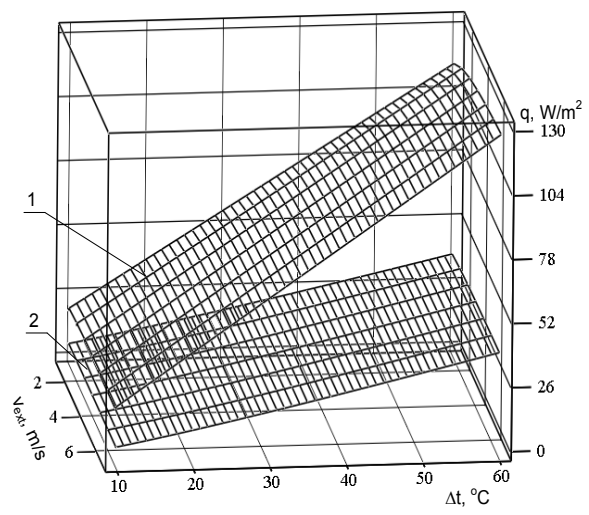

b)

Fig. 3. Relation between given resistance to heat transfer $R$ (a) and specific heat losses $q$ (b) in the transparent area of a window according to the formula $4 \mathrm{M} 1 \times 10 \times 4 \mathrm{M} 1 \times 10 \times 4 \mathrm{M} 1$ in the event of natural convection on the inner surface of the window: 1 - without screens (control); 2 - with 3 metal screens mounted on the outer surface.

\section{Mathematical simulation of dynamic heating in buildings with windows featuring heat reflecting screens}

We developed a mathematical simulation of dynamic heating in an electric substation build-ing with adjustable window resistance to heat transfer, taking into account non-linear dependence of resistance to heat transfer in transparent structures on indoor and outdoor air parameters and adjustable window design during a 24-hour period. We also determined the energy efficiency of using heat reflecting screens with windows and further reduction of ambient temperature during non-working hours (for example, in production facilities and workshops used only during day shifts).

Fig. 4 and 5 show the results of heat exchange simulation through windows at an industrial facility in Moscow (for January conditions), with screens, lowering of indoor air temperature during non-working hours and use of ACS (air conditioning system) to maintain a dynamic indoor environment.

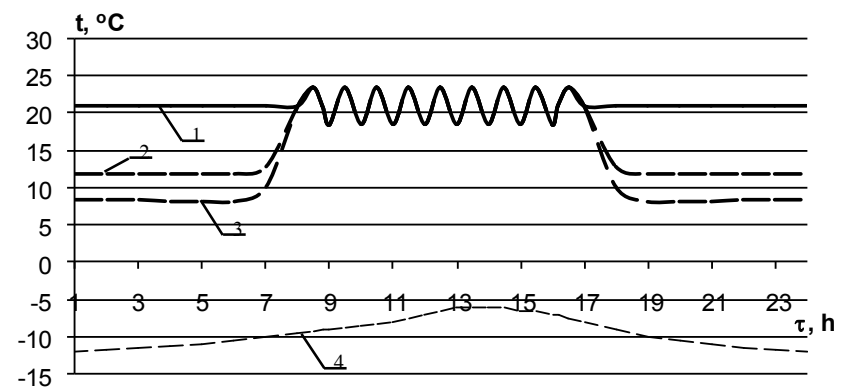

Fig. 4. Changes in indoor and outdoor air temperature over a 24-hour period: 1 - control indoor air temperature $\left(t_{s t b}=\bar{t}_{\text {die }}=21^{\circ} \mathrm{C}\right) ; 2$ - with temperature lowered to $t_{s t b}=12{ }^{\circ} \mathrm{C} ; 3$ - same with $t_{s t b}$ lowered to minimum possible temperature assuming prevention of condensation; 4 - outdoor air temperature (stb-setback mode; die-dynamic indoor environment). 


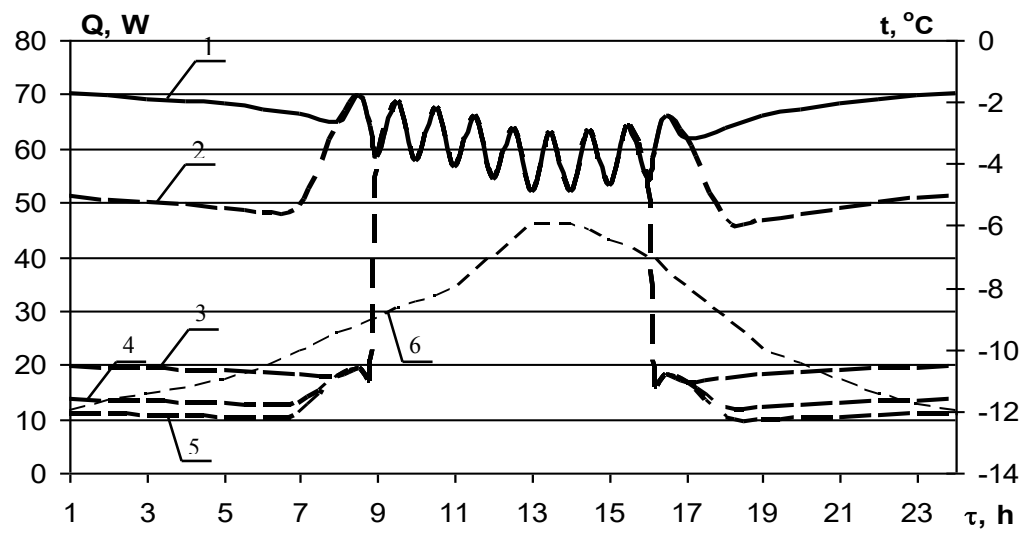

Fig. 5. Changing heat losses $Q$ through $1 \mathrm{~m}^{2}$ of window surface over 24 hours: 1 - control; 2 - with indoor air temperature reduced to $t_{s t b}=12^{\circ} \mathrm{C} ; 3$ - using screens during night time; 4 - with screens and indoor air temperature lowered to $t_{s t b}=12{ }^{\circ} \mathrm{C}$ during night time; 5 - using screens at minimal indoor air temperature $t_{s t b \text {. min }}$ during night time; 6 - outdoor air temperature.

On the basis of our simulation (Fig. 4 and 5) we may conclude that a major contribution to reducing heat losses through window structures is achieved by using heat reflecting screens (losses reduced 3.5 times). Additional heat loss reduction in setback heating mode (with the use of screens) permitted a fivefold reduction in transfer losses. Heat loss changes during a whole day are also related to fluctuating outdoor air temperatures.

\section{Conclusion}

Reducing transmission heat losses through the use of window screens and reduced air temperature during non-working hours significantly increases energy efficiency in the functioning of systems intended to maintain a dynamic indoor environment, with a $30-40 \%$ reduction in annual heating costs. Using a simulation of the thermal condition of a digital transformer enables us to more accurately determine the required air renewal in electric substation buildings.

This research was carried out at Ivanovo State Power Engineering University with the help of a grant from the Russian Scientific Foundation (Project No. 17-79-10455).

\section{References}

1. R. Tabakaev, I. Shanenkov, A. Kazakov, A. Zavorin, J. Anal. Appl. Pyrolysis, 124 (2017), DOI: 10.1016/j.jaap.2017.02.016

2. M. Gaydabrus, I. Razov, R. Tabakaev, V. Lebed, MATEC Web Conf., 110 (2017), DOI: $10.1051 /$ matecconf $/ 201711001030$

3. V.D. Lebedev, A.A. Yablokov, IOP Conference Series: MSE, 177 (2017)

4. V. Lebedev, V. Zhukov, A. Yablokov, IOP Conference Series: MSE, 93 (2015)

5. V.V. Lovtsov, Yu.N. Khomutetsky, Systems of conditioning of dynamic micro-climate of premises (Stroiizdat, Leningrad, 1991)

6. V.M. Zakharov, V.V. Tyutikov, N.N. Smirnov, B. Flament, IOP Conference Series: MSE, 93 (2015), DOI: 10.1088/1757-899X/93/1/012015

7. N. Smirnov, V. Tyutikov, V. Zakharov, MATEC Web Conf., 110 (2017), DOI: $10.1051 /$ matecconf/201711001096 